\title{
EXPERIMENTAL INVESTIGATION ON CHROMIUM(VI) REMOVAL FROM AQUEOUS SOLUTION USING ACTIVATED CARBON RESORCINOL FORMALDEHYDE XEROGELS
}

\author{
Eghe A. Oyedoh ${ }^{a, b, *}$, Michael C. EKwonu ${ }^{c}$ \\ ${ }^{a}$ School of Chemistry and Chemical Engineering, Queen's University Belfast, Northern Ireland, United Kingdom \\ ${ }^{b}$ Department of Chemical Engineering, University of Benin, Benin City, Edo State, Nigeria \\ ${ }^{c}$ Department of Chemical \& Petroleum Engineering, Afe Babalola University, Ado-Ekiti, Nigeria \\ * corresponding author: egheoyedoh@uniben.edu
}

\begin{abstract}
The adsorption of chromium(VI) metal ion in aqueous solutions by activated carbon resorcinol formaldehyde xerogels $(\mathrm{ACRF})$ was investigated. The results showed that pore structure, surface area and the adsorbent surface chemistry are important factors in the control of the adsorption of chromium(VI) metal ions. The isotherm parameters were obtained from plots of the isotherms and from the application of Langmuir and Freundlich Isotherms. Based on regression analysis, the Langmuir isotherm model was the best fit. The maximum adsorption capacity of ACRF for chromium (VI) was $241.9 \mathrm{mg} / \mathrm{g}$. The pseudo-second-order kinetic model was the best fit to the experimental data for the adsorption of chromium metal ions by activated carbon resorcinol formaldehyde xerogels. The thermodynamics of $\mathrm{Cr}(\mathrm{VI})$ ions adsorption onto ACRF was a spontaneous and endothermic process.

Keywords: Adsorption, Chromium(VI) ion, Langmuir isotherm, Freundlich isotherm, Activated carbon resorcinol formaldehyde xerogels (ACRF).
\end{abstract}

\section{INTRODUCTION}

Chromium is used in various industries such as the metallurgical industry (steel, ferro- and nonferrous alloys), refractories (chrome and chrome-magnesite), and in the chemical industry (pigments, electroplating and tanning) [1. As a result of these industrial processes, large amounts of chromium compounds are discharged into the environment. These compounds are toxic and have negative effects on humans and the environment. Persistent exposure to $\mathrm{Cr}(\mathrm{VI})$ causes cancer in the digestive tract and lungs, and may cause other health problems, for instance skin dermatitis, bronchitis, perforation of the nasal septum, severe diarrhoea, and haemorrhaging [2, 3]. The maximum level for chromium in drinking water permitted by the World Health Organization (WHO) is $0.05 \mathrm{mg} / \mathrm{L}$ [4].

$\mathrm{Cr}(\mathrm{III})$ and $\mathrm{Cr}(\mathrm{VI})$ species are the two stable forms of chromium present in the environment. They have different chemical, biological and environmental characteristics. The most toxic form of chromium is $\mathrm{Cr}(\mathrm{VI})$, which exists with oxygen as chromate $\mathrm{CrO}_{4}{ }^{2-}$ or dichromate $\mathrm{Cr}_{2} \mathrm{O}_{7}{ }^{2-}$ oxyanions. $\mathrm{Cr}(\mathrm{VI})$ compounds are highly soluble and mobile. $\mathrm{Cr}$ (III) is less mobile, less toxic and is mainly found bound to organic matter in soil and aquatic environments [5].

Typical methods for the removal of dissolved heavy metals from aqueous solution include chemical precipitation, chemical oxidation or reduction, filtration, ion exchange, electrochemical treatment and application of membrane technology. However, these processes have some major drawbacks, which include incomplete metal removal, requirements for expensive equipment and monitoring system, high reagents and energy re- quirement and generation of toxic sludge with special disposal requirements, especially with the application of low cost adsorbents [6].

Adsorption can be an effective method for the removal of chromium from aqueous solution, especially in combination with suitable regeneration steps, which resolves the problems associated with sludge disposal and makes the process more economically viable [6]. Previous studies on the removal of $\mathrm{Cr}(\mathrm{VI})$ using activated carbons produced from coconut shells [7], clays [8], wheat bran [9], rice husk [10], tyres and sawdust [11, etc. have been reported in the literature.

This study investigates the adsorption of chromium(VI) onto activated carbon resorcinol formaldehyde xerogels using the Langmuir and Freundlich isotherms. The kinetics of adsorption was fitted with pseudo-firstorder and pseudo-second-order and the controlling rate of adsorption described by intra-particle diffusion.

\section{MATERIAL AND METHODS}

\subsection{MATERIAL}

All chemical reagents and materials used were of analytical grade. Deionised water $(18.0 \Omega)$ was used as solvent in the preparation of stock solutions of chromium metal ions by dissolving $2.828 \mathrm{~g}$ of potassium dichromate in $1 \mathrm{dm}^{3}$ of deionised water.

\subsection{SyNTHESIS OF ACTIVATED CARBON RESORCINOL FORMALDEHYDE XEROGELS}

Activated carbon obtained from the synthesis of resorcinol formaldehyde xerogels (ACRF) was used for the adsorption studies [12]. The RF xerogels 
were synthesised from the polycondensation of resorcinol, $\mathrm{C}_{6} \mathrm{H}_{4}(\mathrm{OH})_{2}(\mathrm{R})$, with formaldehyde $\mathrm{HCHO}$ (F) according to the method proposed by Pekala et al. [13, 14, RF solutions were prepared by mixing resorcinol $(\mathrm{R})$, formaldehyde $(\mathrm{F})$, sodium carbonate $\mathrm{Na}_{2} \mathrm{CO}_{3}(\mathrm{C})$ and distilled water. The solution was mixed vigorously for $45 \mathrm{~min}$. The resorcinol/formaldehyde ratio $\mathrm{R} / \mathrm{F}$ was fixed at 0.5 , while the molar ratio of $\mathrm{R} / \mathrm{C}$ and the ratio of $\mathrm{R} / \mathrm{W}(\mathrm{g} / \mathrm{cm})$ were varied. The homogeneous clear solution was then poured into sealed glass vials to avoid water evaporating during the gelation process. The sealed vials were then placed in an oven set at $25^{\circ} \mathrm{C}$ for $24 \mathrm{~h}$. Oven temperature was then increased to $60^{\circ} \mathrm{C}$ for $48 \mathrm{~h}$, and then finally it was increased to $80^{\circ} \mathrm{C}$ for an additional $24 \mathrm{~h}$ to complete the curing process. The wet gels were then removed from the oven and allowed to cool to room temperature. In order, to remove water from the pores of the gels, the gels were immersed in acetone for solvent exchange at room temperature for three days. After the third day, the acetone was poured out and the gels were placed in a vacuum oven for drying. The gels were dried in a vacuum oven at $64^{\circ} \mathrm{C}$ for 3 days.

\subsection{Adsorption STUdies}

All adsorption experiments were carried out with batch reactors (glass bottles and beakers). Stock solutions (1000 ppm) of $\mathrm{Cr}(\mathrm{VI})$ metal ions were prepared. Different concentrations of standard solutions $(25,50$, 100, 150, 200 and $250 \mathrm{ppm}$ ) were prepared by appropriate dilutions of the stock solutions with deionised water. Chromium (VI) concentrations were analysed at $540 \mathrm{~nm}$ wavelength using HACH-DR-2800 UV visible spectrophotometer with 1, 5-diphenylcarbazide reagent. The reagent was prepared by using $250 \mathrm{mg}$ of 1,5-diphenylcarbohydrazide which was dissolved in $50 \mathrm{ml}$ of methanol (HPLC-grade). $250 \mathrm{ml}$ of $\mathrm{H}_{2} \mathrm{SO}_{4}$ solution (contains $14 \mathrm{ml}$ of $98 \% \mathrm{H}_{2} \mathrm{SO}_{4}$ ) was added into the above solution, which was then diluted with deionised water to $500 \mathrm{ml}$.

\subsection{Adsorption isotherms}

Experimental data obtained from the batch tests were analyzed using the Langmuir and Freundlich isotherms to determine the isotherm model that described the experimental data more accurately.

Langmuir Isotherm. The Langmuir isotherm assumes a monolayer, uniform, and finite adsorption site and therefore saturation is reached, beyond which no further adsorption takes place. It is also based on the assumption that there is no interaction between the molecules adsorbed on neighbouring sites [15]. The model developed by Langmuir (1916) is given by:

$$
q_{e}=\frac{q_{\max } b C_{e}}{1+b C_{e}}
$$

The very important characteristic of the Langmuir isotherm can be expressed in terms of a dimensionless constant called the separation factor [6, 16]:

$$
R_{L}=\frac{1}{1+b C_{o}}
$$

Freundlich Isotherm. The Freundlich isotherm is an empirical equation for multilayer, heterogeneous adsorption sites [17]. The Freundlich isotherm is given by:

$$
q_{e}=K_{F} C_{e}^{\frac{1}{n}}
$$

\section{Results AND Discussion}

\subsection{EFFECT OF INITIAL PH}

The effect of $\mathrm{pH}$ on the adsorption of the $\mathrm{Cr}(\mathrm{VI})$ metal ions was studied with the $\mathrm{pH}$ varied from 2.0-11.0. The studies were performed with constant initial metal ions of $100 \mathrm{ppm}$, adsorbent dose of $1 \mathrm{~g} / \mathrm{L}$ solution and contact time of $72 \mathrm{~h}$.

The adsorption of chromium(VI) (Fig. 1) increases with the $\mathrm{pH}$ to a maximum at $\mathrm{pH} 3$, and thereafter decreases with further increase in $\mathrm{pH}$. This shows that adsorption of chromium ions is $\mathrm{pH}$ dependent. The maximum adsorption at $\mathrm{pH} 3$ may be attributed to the existence of chromium ions as $\mathrm{HCrO}_{4}{ }^{-}$which is the dominant form of $\mathrm{Cr}(\mathrm{VI})$ at $\mathrm{pH}$ 3. The high adsorption of $\mathrm{Cr}(\mathrm{VI})$ at $\mathrm{pH} 3$ might be a result of electrostatic attraction between positively charged groups of the ACRF surface and $\mathrm{HCrO}_{4}{ }^{-}$. This can also be attributed to fact that the surface charge on the ACRF. The $\mathrm{pH}_{z p c}$ of ACRF is at 9.19 and below this $\mathrm{pH}$, the surface charge of the ACRF is positive. Hence, adsorption of $\mathrm{Cr}(\mathrm{VI})$ might also be due to electrostatic attraction between positively charged adsorbent and negatively charged $\mathrm{HCrO}_{4}{ }^{-}$[18. As the $\mathrm{pH}$ increased, the overall surface charge on the adsorbents became negative and adsorption decreased [19]. The decrease in removal at higher $\mathrm{pH}$ may be due to the abundance of $\mathrm{OH}^{-}$ions which compete with the negatively charged $\mathrm{Cr}(\mathrm{VI})$ species for the active sites on the ACRF.

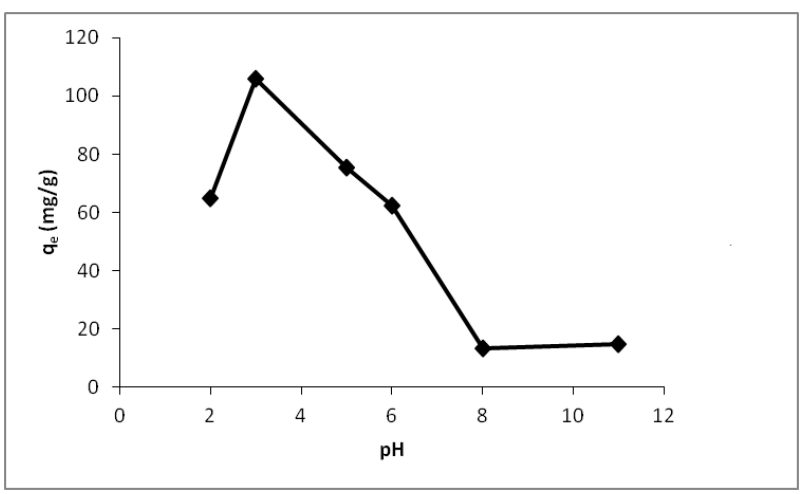

Figure 1. Effect of $\mathrm{pH}$ on adsorption of $\mathrm{Cr}(\mathrm{VI})$ ions 


\subsection{EFFECT OF INITIAL CHROMiUm(VI) CONCENTRATION ON ACRF}

The effect of initial chromium metal ion concentration on the adsorption was studied at optimum the $\mathrm{pH}$ of 3 which was observed from a previous study. The experimental data for the adsorption of $\mathrm{Cr}(\mathrm{VI})$ onto activated carbon resorcinol formaldehyde xerogels were fitted to the Langmuir and Freundlich isotherms using non-linear regression analysis. The isotherm parameters are given in Table 1 Langmuir isotherm (Fig. 2) was seen to have a better fit based on non-linear regression analysis.

The value of the separation factor, $R_{L}$, determines the type of isotherm either to be favourable $\left(0<R_{L}<1\right)$, linear $\left(R_{L}=1\right)$, unfavourable $\left(R_{L}>1\right)$ or irreversible $\left(R_{L}=0\right)$ [20. The low value of $R_{L}(0.000049)$ showed that the adsorption of chromium(VI) onto ACRF was favourable (Table 1).

\subsection{EFFECT OF TEMPERATURE ON CHROMIUM(VI) ADSORPTION}

The effect of temperature on the adsorption of metal ions was carried out with the temperature varied from $20{ }^{\circ} \mathrm{C}(293 \mathrm{~K})$ to $60{ }^{\circ} \mathrm{C}(333 \mathrm{~K})$, with initial concentration of $25-250 \mathrm{ppm}$, adsorbent dosage of $1 \mathrm{~g} / \mathrm{L}$ and optimal $\mathrm{pH}$. The adsorption of $\mathrm{Cr}(\mathrm{VI})$ ions was found to increase with an increase in temperature range $20-60{ }^{\circ} \mathrm{C}$ (Fig. 3). This increase in adsorption capacity of ACRF is an indication of an endothermic process 21. This might be a result of complexation and reduction reactions [22. Also, diffusion is an

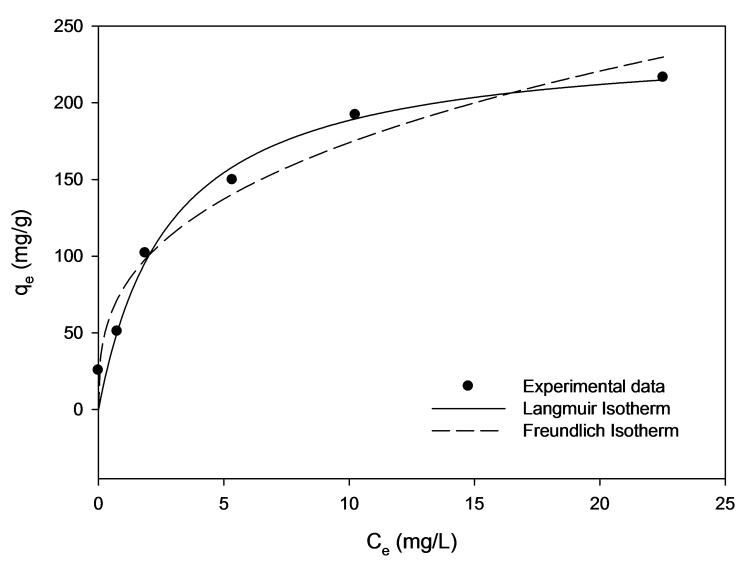

Figure 2. Application of Langmuir and Freundlich Isotherms to adsorption of $\mathrm{Cr}(\mathrm{VI})$ ions

\begin{tabular}{cc}
\hline Langmuir Isotherm & Freundlich Isotherm \\
\hline$q_{\max }=241.9$ & $K_{F}=79.06$ \\
$b=0.3529$ & $1 / n=0.3426$ \\
$R_{L}=0.000049$ & $R^{2}=0.9441$ \\
$R^{2}=0.9740$ & \\
\hline
\end{tabular}

TABLE 1. Isotherm parameters for $\mathrm{Cr}(\mathrm{VI})$ adsorption onto ACRF endothermic process and an increase in temperature increases the diffusion rate of the adsorbate molecules across the external boundary layers and into the pores of ACRF. Similar results were observed with adsorption of $\mathrm{Cr}(\mathrm{VI})$ onto activated carbon [23].

\subsection{EFFECT OF CONTACT TIME}

The effect of contact time on the adsorption of $\mathrm{Cr}(\mathrm{VI})$ was studied by varying the contact time from 0 420 min under $\mathrm{pH}$ of 3 . In Fig. 4, it was seen that the uptake of the metal ions increased with increasing contact time until equilibrium was reached. The adsorption of $\mathrm{Cr}(\mathrm{VI})$ ions initially increased rapidly and then reached equilibrium. The optimum chromium removal was $74.86 \%$ at $60 \mathrm{~min}$ for $25 \mathrm{ppm}$ and $77.21 \%$ at $240 \mathrm{~min}$ for $200 \mathrm{ppm}$; it was $100 \%$ at $420 \mathrm{~min}$ for $25 \mathrm{ppm}$ and $83 \%$ at $420 \mathrm{~min}$ for $200 \mathrm{ppm}$.

\subsection{Adsorption KinETICS}

The pseudo-first-order, pseudo-second-order and intraparticle diffusion models were used to fit the experimental data for the different initial chromium ion concentrations. The results of pseudo-second-order kinetics observed in this study are supported by the findings of Bhattacharya $[8$. The values of the second

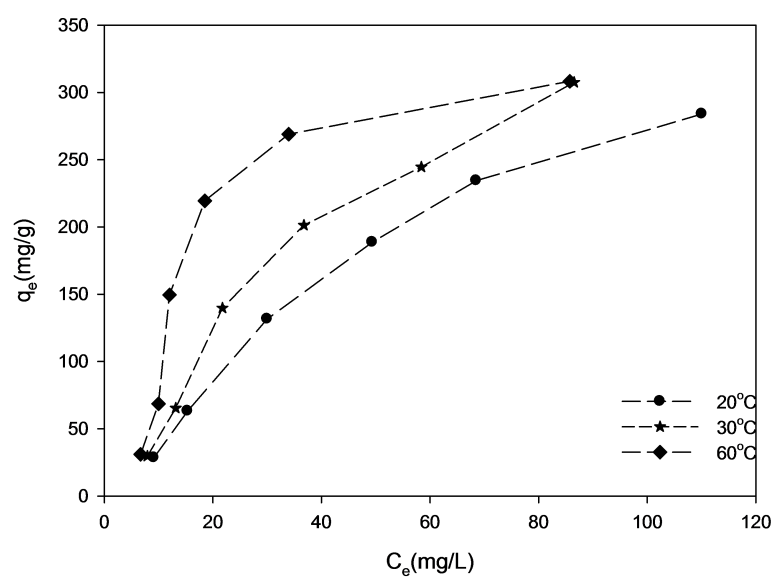

FIGURE 3. Effect of temperature on the adsorption of $\mathrm{Cr}(\mathrm{VI})$

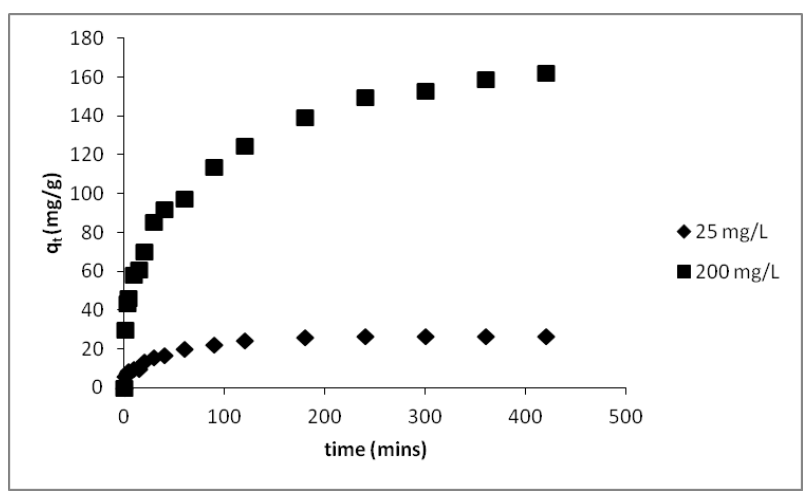

FIGURE 4. Effect of contact time on the adsorption of $\mathrm{Cr}(\mathrm{VI})$. 


\begin{tabular}{cccccccccc}
\hline $\begin{array}{c}\mathrm{C}_{o} \\
(\mathrm{mg} / \mathrm{L})\end{array}$ & \multicolumn{2}{c}{ Pseudo-first-order } & & \multicolumn{2}{c}{ Pseudo-second-order } & & \multicolumn{2}{c}{ Intra-particle Diffusion } \\
\cline { 2 - 3 } & $k_{1}$ & $R^{2}$ & & $k_{2}$ & $h$ & $R^{2}$ & & $k_{i}$ & $R^{2}$ \\
\hline 25 & 0.1705 & 0.9768 & & 0.0136 & 3.2938 & 0.9743 & & 1.5737 & 0.7411 \\
50 & 0.0935 & 0.9742 & & 0.0041 & 3.3706 & 0.9833 & & 2.2374 & 0.7888 \\
150 & 0.0706 & 0.9138 & & 0.0015 & 8.3693 & 0.9647 & & 3.0394 & 0.7584 \\
200 & 0.0530 & 0.9499 & & 0.0010 & 5.7566 & 0.9864 & & 3.3937 & 0.8209 \\
\hline
\end{tabular}

TABLE 2. Kinetic models and parameters of adsorption of $\mathrm{Cr}(\mathrm{VI})$

order rate constants $\left(k_{2}\right)$ were found to decrease from $0.0136-0.0010 \mathrm{~g} \mathrm{mg}^{-1} \mathrm{~min}^{-1}$ as the initial concentration increased from $25-200 \mathrm{mg} / \mathrm{L}$. This indicated that the process is highly concentration dependent 24 .

\subsection{MECHANISM OF ADSORPTION}

As seen in Fig. 5 the ACRF spectra displayed a change of intensity and shift of the carbonyl stretching band around $1630 \mathrm{~cm}^{-1}$ after the contact with chromium solution. This is a result of the complexation of the carbonyl group with chromium. Another shift can be observed as a result of complexation of the oxygen from the carboxyl $\mathrm{C}-\mathrm{O}$ bond at wave numbers 1166 and $1066 \mathrm{~cm}^{-1}$. The $\mathrm{O}-\mathrm{H}\left(3434 \mathrm{~cm}^{-1}\right)$ and $\mathrm{C}-\mathrm{O}$ (2390 and $2361 \mathrm{~cm}^{-1}$ ) band absorption peaks are observed to shift when ACRF is loaded with chromium. Two new peaks were observed in FTIR spectra of $\mathrm{Cr}$ (VI)-loaded sorbents, which is attributed to $\mathrm{Cr}-\mathrm{O}$ and $\mathrm{Cr}=\mathrm{O}$ bonds of chromate anions, and which confirms the sorption of $\mathrm{Cr}(\mathrm{VI})$ onto the activated carbon resorcinol formaldehyde xerogel (ACRF) at 719 and $910 \mathrm{~cm}^{-1}$ [25].

The mechanism of chromium(VI) adsorption from aqueous solution is attributed to physical adsorption by electrostatic attraction between positively charged adsorption sites in the adsorbent and the negatively charged $\mathrm{Cr}(\mathrm{VI})$ species.

It can be seen that carboxyl groups are involved in the removal mechanism, as shown with the FTIR

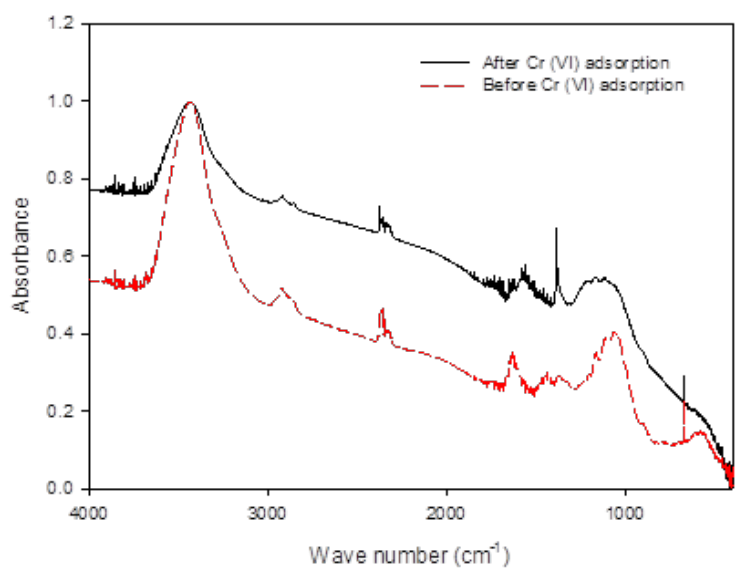

FIGURE 5. FTIR spectra of ACRF adsorbent (A) before and (B) after $\mathrm{Cr}(\mathrm{VI})$ adsorption. results [26]. Other functional groups may also be involved in metal ions adsorption. From the SEM (Figure 6a (Unloaded ACRF)), it can be seen that ACRF has a large surface area. The chromium metal ions were adsorbed onto the pores and surfaces of adsorbent as shown by the SEM image (Figure 6p (loaded ACRF)). The EDX analyses of ACRF before adsorption were: C: $97.48 \%$; O: $2.31 \%$; Na: $0.21 \%$. The EDX analyses for Cr(VI)-loaded ACRF were: C: $39.56 \%$; O: $3.0 \%$; Na: $0.05 \%$; Cr: $57.38 \%$.

\subsection{AdSORPTION THERMODYNAMICS}

The thermodynamics parameters such as Gibbs free energy, enthalpy change and entropy change were obtained using the following equations [6]:

$$
\begin{aligned}
K_{c} & =\frac{q_{e}}{C_{e}}, \\
\Delta G^{o} & =-R T \ln K_{c}, \\
\ln K_{c} & =\frac{\Delta S^{o}}{R}-\frac{\Delta H^{o}}{R T} .
\end{aligned}
$$

The value of $\Delta H^{o}$ and $\Delta S^{\circ}$ are obtained from the slope and intercept of the linear Van't Hoff plot of $\ln K_{c}$ versus $1 / T(6)$. Table 3 shows the calculated values of the thermodynamic parameters for the adsorption of $\mathrm{Cr}(\mathrm{VI})$ on $\mathrm{ACRF}$.

The negative values of $\Delta G^{o}$ at various temperatures indicate the spontaneous nature of the adsorption process. The increase in $\Delta G^{o}$ with temperature clearly indicates a more favourable adsorption at high temperature. The positive value of $\Delta H^{o}$ indicates the adsorption process is endothermic. More so, the positive value of $\Delta S^{o}$ indicates the degree of randomness of the system solid-solution interface during the adsorption process. Similar results were reported for $\mathrm{Cr}(\mathrm{VI})$ adsorption [6, 27]. As reported by Malkoc

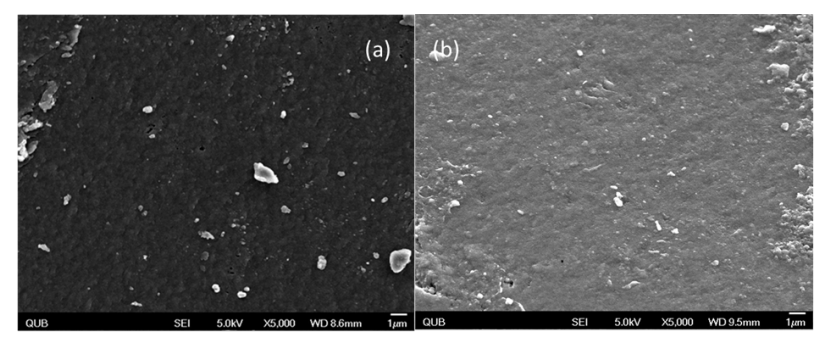

Figure 6. SEM images of ACRF (a) before Cr(VI) adsorption and (b) after $\mathrm{Cr}(\mathrm{VI})$ adsorption. 


\begin{tabular}{ccccc}
\hline $\mathrm{T}$ & $\mathrm{K}_{c}$ & $\Delta G^{o}$ & $\Delta H^{o}$ & $\Delta S^{o}$ \\
\hline 293 & 3.0398 & -2.71 & 7.51 & 0.0355 \\
303 & 4.0450 & -3.52 & & \\
333 & 4.6185 & -4.24 & & \\
\hline
\end{tabular}

TABLE 3. Thermodynamics parameters for $\mathrm{Cr}(\mathrm{VI})$ adsorption onto ACRF

and Nuhoglu [27, the positive value of $\Delta S^{\circ}$ reflects the affinity of the adsorbent for $\mathrm{Cr}(\mathrm{VI})$ ions and suggests some structural changes in chromium and the adsorbent.

\section{Conclusions}

The effect of initial Chromium(VI) metal ion concentration on the adsorption on ACRF was studied at optimum $\mathrm{pH}$ observed from a previous study. The Langmuir isotherm was seen to have a better fit based on non-linear regression analysis. The maximum adsorption capacity of ACRF for Chromium(VI) was $241.9 \mathrm{mg} / \mathrm{g}$. The pseudo-second-order kinetic model was the best fit to the experimental data for the adsorption of chromium (VI) metal ions by activated carbon resorcinol formaldehyde xerogels. The optimal removal was $74.86 \%$ at $60 \mathrm{~min}$ for $25 \mathrm{ppm}$ and $77.21 \%$ at $240 \mathrm{~min}$ for $200 \mathrm{ppm}$. Different mechanisms were responsible for Chromium(VI) metal ion adsorption. The results showed that the adsorption of $\mathrm{Cr}(\mathrm{VI})$ is a result of electrostatic attraction, ion exchange/complexation and reduction reactions. The thermodynamic analysis showed that the Chromium adsorption process was endothermic and spontaneous in nature.

\section{LIST OF SYMBOLS}

$q_{e}$ Amount of solute adsorbed per unit weight of adsorbent $[\mathrm{mg} / \mathrm{g}]$

$C_{e}$ Equilibrium concentration of solute in the bulk solution $[\mathrm{mg} / \mathrm{L}]$

$b$ Constant related to the free energy of adsorption $[\mathrm{L} / \mathrm{mg}]$

$q_{\max }$ maximum adsorption capacity $[\mathrm{mg} / \mathrm{L}]$

$C_{o}$ initial $\mathrm{Cr}(\mathrm{VI})$ concentration $[\mathrm{mg} / \mathrm{L}]$

$K_{F} \quad$ Freundlich constant $[\mathrm{mg} / \mathrm{g}]$

$1 / n$ Heterogeneity factor $[\mathrm{mg} / \mathrm{L}]$

$k_{1}$ pseudo-first-order rate constant $\left[\mathrm{min}^{-1}\right]$

$k_{2} \quad$ pseudo-second-order rate constant $[\mathrm{g} / \mathrm{mg} \mathrm{min}]$

$k_{i} \quad$ Intra-particle diffusion constant $\left[\mathrm{mg} \mathrm{g}^{-1} \mathrm{~min}^{-05}\right]$

$R_{L}$ Separation factor

$T$ Temperature $[\mathrm{K}]$

$R \quad$ Universal gas constant, $8.314 \mathrm{~J} \mathrm{~mol}^{-1}$

$K_{c}$ Equilibrium constant

$\Delta H$ Enthalpy change $\left[\mathrm{kJ} \mathrm{mol}^{-1}\right]$

$\Delta S$ Entropy change $\left[\mathrm{kJ} \mathrm{mol}^{-1} \mathrm{~K}^{-1}\right]$

$\Delta G^{o}$ Gibbs free energy change $\left[\mathrm{kJ} \mathrm{mol}^{-1}\right]$

$R^{2} \quad$ Coefficient of determination

\section{REFERENCES}

[1] J. Kotaś, Z. Stasicka. Chromium occurrence in the environment and methods of its speciation.

Environmental Pollution 107(3):263 - 283, 2000.

[2] A. Albadarin, C. Mangwandi, A. Al-Muhtaseb, et al. Kinetic and thermodynamics of chromium ions adsorption onto low-cost dolomite adsorbent. Chemical Engineering Journal 179:193 - 202, 2012.

[3] M. Owlad, M. K. Aroua, W. A. W. Daud, S. Baroutian. Removal of Hexavalent Chromium-Contaminated Water and Wastewater: A Review. Water, Air, and Soil Pollution 200(1):59-77, 2009. DOI:10.1007/s11270-008-9893-7

[4] L. Wang, C. Lin. Adsorption of chromium (III) ion from aqueous solution using rice hull ash. Journal of the Chinese Institute of Chemical Engineers 39(4):367 $373,2008$.

[5] A. Shanker, C. Cervantes, H. Loza-Tavera, S. Avudainayagam. Chromium toxicity in plants. Environmental International 31(5):739 - 753, 2005.

[6] H. Demiral, İ. Demiral, F. Tümsek, B. Karabacakoğlu. Adsorption of chromium(VI) from aqueous solution by activated carbon derived from olive bagasse and applicability of different adsorption models. Chemical Engineering Journal 144(2):188-196, 2008. DOI:10.1016/j.cej.2008.01.020

[7] S.-J. Park, Y.-S. Jang. Pore Structure and Surface Properties of Chemically Modified Activated Carbons for Adsorption Mechanism and Rate of $\mathrm{Cr}(\mathrm{VI})$. Journal of Colloid and Interface Science 249(2):458-463, 2002. DOI:10.1006/jcis.2002.8269

[8] A. Bhattacharya, S. Mandal, S. Das. Adsorption of Zn (II) from aqueous solution by using different adsorbents. Chemical Engineering Journal 123(1-2):43-51, 2006.

[9] M. Nameni, M. R. Alavi Moghadam, M. Arami. Adsorption of hexavalent chromium from aqueous solutions by wheat bran. International Journal of Environmental Science \& Technology 5(2):161-168, 2008. DOI:10.1007/BF03326009

[10] N. R. Bishnoi, M. Bajaj, N. Sharma, A. Gupta. Adsorption of $\mathrm{Cr}(\mathrm{VI})$ on activated rice husk carbon and activated alumina. Bioresource Technology 91(3):305307, 2004. DOI:10.1016/S0960-8524(03)00204-9.

[11] N. K. Hamadi, X. D. Chen, M. M. Farid, M. G. Lu. Adsorption kinetics for the removal of chromium(VI) from aqueous solution by adsorbents derived from used tyres and sawdust. Environmental Chemical Engineering 84(2):95-105, 2001. DOI:10.1016/S1385-8947(01)00194-2

[12] E. Oyedoh, A. Albadarin, G. Walker, et al. Preparation of Controlled Porosity Resorcinol Formaldehyde Xerogels for Adsorption Applications. Chemical Engineering Transactions 32:1651 - 1656, 2013.

[13] M. Mirzaeian, P. J. Hall, EPSRC (Funder). Preparation of controlled porosity carbon aerogels for energy storage in rechargeable lithium oxygen batteries. Electrochimica Acta 54(28):7444-7451, 2009.

DOI:10.1016/j.electacta.2009.07.079 
[14] R. W. Pekala, D. W. Schaefer. Structure of organic aerogels. 1. Morphology and scaling. Macromolecules 26(20):5487-5493, 1993. DOI:10.1021/ma00072a029

[15] I. Langmuir. The Constitution and fundamental properties of solids and liquids. Part I, Solids. Journal of the American Chemical Society 38(11):2221-2295, 1916. DOI:10.1021/ja02268a002

[16] K. R. Hall, L. C. Eagleton, A. Acrivos, T. Vermeulen. Pore- and Solid-Diffusion Kinetics in Fixed-Bed Adsorption under Constant-Pattern Conditions. Industrial $\mathcal{E}$ Engineering Chemistry Fundamentals 5(2):212-223, 1966. DOI:10.1021/i160018a011.

[17] H. Freundlich. Over the adsorption in solution. $J$ Phy Chem 57:385 - 470, 1906.

[18] A. Albadarin, A. Al-Muhtaseb, N. Al-laqtah, et al. Biosorption of toxic chromium from aqueous phase by lignin: mechanism, effect of other metal ions and salts Chemical Engineering Journal 169(1-3):20-30, 2011.

[19] B. Singha, S. Das. Biosorption of Cr (VI) ions from aqueous solutions: Kinetics, equilibrium, thermodynamics and desorption studies. Colloids and Surfaces B: Biointerfaces 84(1):221 - 232, 2011.

[20] M. Belhachemi, F. Addoun. Comparative adsorption isotherms and modeling of methylene blue onto activated carbons. Applied Water Science 1(3):111-117, 2011. DOI:10.1007/s13201-011-0014-1

[21] K. S. Rao, G. R. Chaudhury, B. K. Mishra. Kinetics and equilibrium studies for the removal of cadmium ions from aqueous solutions using Duolite ES 467 resin. International Journal of Mineral Processing 97(1-4):68 73, 2010. DOI:10.1016/j.minpro.2010.08.003.

[22] D. Duranoğlu, A. Trochimczuk, U. Bekerb. A comparison study of peach stone and acrylonitrile-divinylbenzene copolymer based activated carbons as chromium (VI) sorbents. Chemical Engineering Journal 165:56 - 63, 2010.

[23] E. Ozdemir, D. Duranoğlu, U. Bekerb, A. Avcıb. Process optimization for Cr (VI) adsorption onto activated carbons by experimental design. Chemical Engineering Journal 172:207 - 218, 2011.

[24] E. Demirbas, N. Dizge, M. Sulak, M. Kobya. Adsorption kinetics and equilibrium of copper from aqueous solutions using hazelnut shell activated carbon. Chemical Engineering Journal 148(2-3):480-487, 2009.

[25] G. Kyzas, M. Kostoglou, N. Lazaridis. Copper and Chromium (VI) removal by chitosan derivatives-Equilibrium and kinetic studies. Chemical Engineering Journal 152(2-3):440-448, 2009.

[26] V. Murphy, S. Tofail, H. Hughes, P. Mcloughlin. A novel study of hexavalent chromium detoxification by selected seaweed species using SEM-EDX and XPS analysis. Chemical Engineering Journal 148(2-3):425-433, 2009.

[27] E. Malkoc, Y. Nuhoglu. Potential of tea factory waste for chromium(VI) removal from aqueous solutions: Thermodynamic and kinetic studies. Separation and Purification Technology 54(3):291-298, 2007. DOI:10.1016/j.seppur.2006.09.017 